\title{
Canadian Urological Association Best Practice Report: Catheter use
}

Lysanne Campeau ${ }^{1}$; Samer Shamout ${ }^{1}$; Richard J. Baverstock ${ }^{2}$; Kevin V. Carlson ${ }^{2}$; Dean S. Elterman ${ }^{3}$; Duane R. Hickling ${ }^{4}$; Stephen S. Steele ${ }^{5}$ Blayne Welk ${ }^{6}$

${ }^{1}$ Department of Urology, Jewish General Hospital, McGill University, Montreal, QC, Canada;

${ }^{2}$ vesia [Alberta Bladder Centre]; Division of Urology, Department of Surgery, University of Calgary, Calgary, AB, Canada; ${ }^{3}$ Division of Urology, University Health Network, Toronto, ON, Canada; ${ }^{4}$ Division of Urology, Department of Surgery, The Ottawa Hospital, Ottawa, ON, Canada; ${ }^{5}$ Queen's University, Kingston, ON, Canada; ${ }^{6}$ University of Western Ontario, London, ON, Canada

Cite as: Can Urol Assoc J 2020 May 8; Epub ahead of print. http://dx.doi.org/10.5489/cuaj.6697

Published online May 8, 2020

***

\section{Introduction}

Catheters are widely used for urinary retention or incontinence and neurogenic lower urinary tract dysfunction (NLUTD). This includes intermittent catheterization (IC), indwelling urethral catheters, and suprapubic catheterization. Both intermittent and indwelling catheterization provide means for long-term effective urinary drainage with the aim to protect the upper urinary tract, improve urinary continence and minimize urinary tract complications. ${ }^{1}$ However, urinary catheters can be associated with an increased risk of urinary tract infections, incontinence, calculi and compromised kidney function.

IC is generally the gold standard method of bladder drainage. Although technology has progressed in the field of catheter design, material and technique, there is limited high quality evidence and good practice recommendations around catheter usage in chronic conditions such as NLUTD. Our objective was to review the evidence around the use of long-term urinary catheters in patients with chronic conditions, and make practice recommendations for physicians in Canada who manage catheters in this population. We pay specific attention to the current best evidence of the available techniques, design, material, and practices of intermittent selfcatheterization and its position in the treatment pathway. 


\section{Methods}

This best practice report provides a brief and comprehensive discussion of studies examining catheter management for impaired bladder emptying in the setting of neurogenic and nonneurogenic lower urinary tract dysfunction. It is based on data obtained from numerous published meta-analyses and original studies identified through literature search using PubMed, Medline, and the Cochrane Library database. The bibliographies of relevant articles were also searched to avoid exclusion of important studies. The following narrative review concentrates on systematic reviews, related guidelines and comparative studies. Articles included in this statement were reviewed using methodology consistent with the Grading of Recommendations Assessment, Development, and Evaluation (GRADE) for evidence synthesis and recommendations. This best practice statement addressed similar subject matter and scope that is of significance to the Canadian urology practice. Competing interest of authors have been considered and addressed.

\section{Types of catheters}

The indications for urinary catheterization may be prolonged, and sometimes irreversible (Table 1). There are two important populations that tend to require catheters. First, approximately 5 to $10 \%$ of residents of long-term care facilities in Canada have bladder dysfunction managed with chronic catheterization. ${ }^{2}$ Second, people with NLUTD from a neurologic lesion may need catheters because of failure to store and/or empty urine from the bladder (which results in incontinence and/or urinary retention).

\subsection{Indwelling catheterization (urethral or suprapubic)}

Optimal bladder management is selected according to anatomical factors and patients' preferences. Indwelling catheters are often used initially after SCI, however patients usually transition to IC if possible. ${ }^{3}$ Despite the problems associated with indwelling catheters, many patients with a SCI switch to these catheters over time. Long-term use of indwelling catheters are often recommended as the last resort, except for quadriplegic patients with impaired dexterity, or those who are bedridden, or in situations where IC is difficult or impossible. ${ }^{4}$

SPC offers certain advantages compared to urethral catheters: it may improve the independence, facilitate engagement in sexual activities and decrease the risk of epididymitis. ${ }^{1}$ The rate of infection and incidence of bacteriuria is not consistently decreased with IC method compared to SPC. Studies have documented high rates (5-10\% per day) of polymicrobial colonization of the urine in patients using indwelling catheters ${ }^{5}$. Some studies have suggested that SPC is associated with a reduced risk of bacteriuria and better patient satisfaction when compared with urethral catheters. ${ }^{6}$ Regular follow-up and surveillance continue to be the backbone of this strategy in order to minimize associated morbidity and improve prognosis. 


\subsection{IC}

IC is accepted worldwide as a standard of care for patients with incomplete bladder emptying. When IC was introduced for SCI patients in the 1940's, nurses initially performed it using an aseptic technique, requiring sterile gloves, single use catheters, and disinfectant cleaning solution. In the 1970's, Lapides suggested that sterility was not important for preventing UTIs, and impractical for patients; he proposed clean IC (IC, which includes only hand washing and regular genital hygiene). ${ }^{7}$ The bladder is drained regularly several times during the day, simulating the physiological bladder filling/emptying cycle. This can also prevent adverse health outcomes, such as recurrent urinary tract infections (UTIs), urinary incontinence (UI), skin complications, and chronic kidney injury. Compared to indwelling catheters, IC can reduce the risk of mechanical urethral erosion, bladder cancer/stones, and urosepsis (table 2).

Despite being preferable to an indwelling urinary catheter, IC can have challenges such as pain, UTI and urethral trauma. Recent studies reported urethral stricture rates in IC users of 4 to $13 \%$ despite using hydrophilic-coated catheters. ${ }^{8}$ Despite the medical advantages of IC, only $37 \%$ of patients remain on this form of bladder management over time. ${ }^{9}$

Factors such as catheter coating and design, reuse, and who performs the catheterization make selection of the ideal catheter difficult. The available literature does not provide convincing evidence regarding the effectiveness of any particular catheter design, technique or strategy.

\section{Catheter-related complications}

\subsection{Catheter-associated infection}

The Infectious Disease Society of America (ISDA) released international clinical practice guidelines for the diagnosis, prevention and treatment of catheter-associated urinary tract infection (CA-UTI) in 2010. ${ }^{10}$ This widely accepted guideline defines CA-UTI as the presence of symptoms or signs compatible with UTI with no other identified source of infection along with $\geq$ $10^{3}$ colony-forming units (cfu) $/ \mathrm{ml}$ of $\geq 1$ bacterial species in a single catheter urine specimen or in a midstream urine specimen from a patient whose urethral, suprapubic, or condom catheter has been removed within the previous 48 hours. Signs and symptoms compatible with CA-UTI include the new onset or worsening of fever, rigors, altered mental status, malaise, or lethargy with no other identified cause, flank pain; costovertebral angle tenderness; acute hematuria; pelvic discomfort; and in those whose catheters have been removed, dysuria, urgent or frequent urination, or suprapubic pain or tenderness. In patients with SCI, increased spasticity, autonomic dysreflexia, or sense of unease are also compatible with CA-UTI. The IDSA guideline does not recommend interpretation of pyuria for defining CA-UTI, differentiating catheter-associated asymptomatic bacteria (CA-ASB) from CA-UTI or serving as a threshold for antimicrobial therapy. 10 
Catheter associated asymptomatic bacteriuria (CA-ASB) is defined by the ISDA as the presence of $\geq 10^{5} \mathrm{cfu} / \mathrm{ml}$ of $\geq 1$ bacterial species in a single catheter urine specimen in a patient without symptoms compatible with UTI. ${ }^{1}$ The incidence of CA-ASB in those with indwelling catheters is $3 \%$ to $8 \%$ per day with CA-ASB being nearly universal by 30 days. ${ }^{11}$ As such, the ISDA recommends against the routine screening of CA-ASB with the exception of selected clinical situations, such as pregnant women. ${ }^{10}$

If there is clinical suspicion of CA-UTI, specimen collection should occur prior to antimicrobial therapy and proceed according to method of bladder management. In general, a catheterized urine specimen is preferable to voided sample as it avoids contamination with periurethral microbes. Patients with indwelling catheters should have their catheter exchanged with immediate collection of a specimen following insertion of the new catheter. This approach has been demonstrated to enhance clinical improvement, minimize symptoms duration, and reduce the frequency of infection relapse. ${ }^{12}$ In the setting of chronic urinary catheterization, the level of colonization is commonly $>10^{5} ;{ }^{13,14}$ therefore culture alone is inadequate for diagnosis of infection. In general, a clinically significant UTI with a chronic indwelling catheter requires consideration of clinical symptoms and severity of illness plus laboratory confirmation (Urine culture $\left.>10^{2} \mathrm{CFU} / \mathrm{mL}\right) .{ }^{15}$ In cases of short-term catheterization, it is considered acceptable to obtain a specimen aseptically through the catheter port. Specimens should never be collected from a catheter drainage bag.

Method of bladder management remains of paramount importance for reduction of CAASB and CA-UTI. ${ }^{10} \mathrm{IC}$ is associated with fewer CA-UTI when compared to other modalities and should therefore be utilized whenever possible. ${ }^{16}$ When IC is not possible, a closed catheter drainage system should be used to reduce CA-ASB and CA-UTI in those with short- or longterm indwelling catheters. Data are insufficient to recommend SPC over urethral catheterization for long-term prevention of CA-ASB and CA-UTI. ${ }^{10}$

\section{Impact of IC catheter type and material on UTIs}

- Hydrophilic vs uncoated catheters. Two recent systematic reviews and meta-analyses explored the risk of UTI associated with hydrophilic catheters (HC) in comparison to polyvinyl chloride catheters (PVC) in adult patients with NLUTD. Shamout et al. reported less frequent UTIs with $\mathrm{HC}$ but this was not statistically significant and there was no significant difference in terms of bacteriuria. ${ }^{17}$ Rognoni et al. reported significantly less UTIs with single-use HC compared to multiple-use PVC catheter (Risk ratio $=0.84 ; 95 \% \mathrm{CI}, 0.75-0.94)$, with the estimated risk reduction turned to be $16 \% .{ }^{18}$ This confirmed the meta-analysis results of Li et al. (Five studies, 462 subjects) which demonstrated a significantly lower UTI incidence in the hydrophilic- group $(\mathrm{OR}=0.36$; 95\% CI, 24\%-54\%; P<.0001). 
Two prospective RCT evaluated UTI risk in children with neurogenic bladder. ${ }^{19,20}$ While Defoor et al. reported a significant lower risk of UTI in the HC group even with singleuse PVC catheter $(9.1 \%$ vs. $51.5 \%$ UTIs per person-year; $\mathrm{p}=0.003){ }^{19}$; Kiddoo et al. found no difference in incidence of symptomatic urinary tract infection between $\mathrm{HC}$ and multiple use PVC catheters. ${ }^{4}$

- Hydrophilic vs hydrophilic catheters. Only one study (27 patients) compared three different types of $\mathrm{HC}$ catheters (Lofric, EasiCat and Flocath). No significant difference in bacteriuria incidence between these three catheters. ${ }^{21}$

- Prelubricated vs non-pre-lubricated catheters. Ginnantoni et al. found that prelubricated catheters (Instantcath) significantly reduce the incidence of UTI ( $7.4 \%$ vs $22.2 \%)$ and bacteriuria ( $14.8 \%$ vs $33.3 \%$ ) when compared to standard PVC catheters. ${ }^{22}$

- Anti-microbial-coated catheter vs non-anti-microbial-coated catheters. Antibiotic and silver-coated catheters appear to only be effective in reducing bacteriuria and UTIs in the short-term. Long-term use of antibiotic and silver-coated catheters increase the risk for antimicrobial resistance and silver toxicity. ${ }^{23}$ Therefore, these are not recommended for routine use.

\section{Impact IC catheterization technique on UTIs}

- Clean vs. aseptic. When analyzing IC techniques, there was a significant reduction in the incidence of UTIs with aseptic versus clean techniques. However, there was no difference in bacteriuria between these techniques. ${ }^{17,24}$

- Single-use vs multiple-use. Studies have estimated that risk of UTI associated with multiple-use catheters is about $70-80 \%$, whereas the risk with single-use catheters is about $40-60 \% .{ }^{25} \mathrm{~A}$ recent RCT evaluated the risk of UTI and bacteriuria among spina bifida patients who used either single-use PVC catheters or reused PVC catheters. There was no significant difference in terms of bacteriuria $(32.4 \%$ vs $23.7 \%, \mathrm{p}=0.398)$ or urinary tract infections $(35.2 \%$ vs $36.8 \%, p=0.877)$ between these two methods of IC. ${ }^{26}$

\section{Summary}

In the era of rapidly advancing medical technology it is surprising to learn that the contemporary urinary catheter has changed very little since its introduction in the 1930s. ${ }^{27} \mathrm{~A}$ number of catheter coatings and physical alterations have been developed in an attempt to prevent biofilm production, CA-bacteriuria and CA-UTI. Unfortunately, no effort has been proven unequivocally successful in clinical studies. ${ }^{28}$ The IDSA does not recommend antimicrobial (silver or antibiotic) coated or hydrophilic urinary catheters for the reduction of CA-ASB or CA-UTI. 


\subsection{Urethral complications}

\subsubsection{Urethral trauma}

Microscopic hematuria, gross hematuria and quantity of epithelial cells left on a catheter after removal have all been used as markers of urethral trauma in the literature. However, definitions of microscopic hematuria have included 1 to 5 red blood cells (RBCs) per high powered field, $>10$ RBCs per high powered field and a simple positive dipstick for blood. ${ }^{29-31}$ Other studies have used only macroscopic bleeding episodes as an indication of urethral trauma. ${ }^{29,32}$

\section{Impact of IC catheter type and material on urethral trauma}

- Hydrophilic vs uncoated catheters. There are six randomized control trials (RCTs) assessing hematuria in patients using either hydrophilic or standard PVC catheters. ${ }^{19,29-33}$ Only one of the RCTs identified a significant decrease in gross bleeding episodes with a hydrophilic catheter versus a PVC catheter. ${ }^{32}$ This difference was not reported in any of the other RCTs. ${ }^{19,29-31,33}$ However, three RCTs identified a significant decrease in microscopic hematuria in patients using a hydrophilic catheter vs non-hydrophilic catheter, with an unknown clinical significance. ${ }^{30,31,33}$

- Hydrophilic vs. hydrophilic. Three RCTs directly compared different types of hydrophilic catheters. (Speedicath $\AA$, Lofric ${ }^{\circledR}$, Easicath $®$ and Flocath ${ }^{\circledR}$ ). ${ }^{21,34,35}$ No difference was seen with regards to microscopic or macroscopic hematuria. However, one study demonstrated a significantly higher withdrawal friction force with Lofric vs Speedicath using number of epithelial cells on the catheter after removal as a marker of urethral trauma. ${ }^{34}$

- Prelubricated vs. non-prelubricated catheters. Two RCTs were identified in the literature comparing prelubricated (Instacath) vs uncoated PVC catheters. ${ }^{22,36}$ In both studies, the results demonstrated that a gel-lubricated non-hydrophilic catheter was superior to the PVC catheter in terms of microscopic hematuria ${ }^{36}$ and epithelial cell counts. ${ }^{22,36}$

Impact of IC catheterization technique on urethral trauma

- Catheter practices (single use versus reuse). Vapnek el al. compared hydrophilic coated catheters (single use) versus PVC catheters (multiple use), they reported significant less hematuria in the hydrophilic coated group ( $27 \% \mathrm{HC}$ vs $35 \% \mathrm{PVC}) .{ }^{30}$ However, this comparison includes two variables (catheter coating and reuse) which makes interpretation difficult.

\section{Summary}

Hydrophilic catheters may cause less urethral trauma with decreased microscopic hematuria, decreased bleeding episodes and fewer epithelial cells on the removed catheter. There is no clear advantage of one hydrophilic catheter versus another in the literature. Furthermore, evidence concerning catherization practices (single use vs multiple use) is inadequate and biased by the 
use of different catheter materials. The information is still limited and further studies are needed in order to enhance the data on this issue.

\subsubsection{Urethral strictures}

The repetitive trauma of IC may lead to urethral stricture formation. The occurrence of strictures in this population has been estimated to be anywhere from $4.2 \%{ }^{37}$ to as high as $25 \%{ }^{38}$ Due to the length of time often required for stricture formation in this population, the available literature is limited. The paucity of information makes direct comparison of PVC, hydrophilic, and prelubricated catheters extremely challenging. Five studies were identified in the literature that looked at stricture formation in the IC population. ${ }^{19,37-40}$

\section{Impact of catheter type and material on urethral strictures}

- Hydrophilic vs uncoated catheters. Though the data on microscopic hematuria, bleeding episodes, and epithelial cell counts would seem to indicate increased trauma with the non-hydrophilic catheters, and thus increased stricture formation, this in not actually reflected in the available literature. Four of the studies did not identify any difference in the rate of stricture formation between hydrophilic and non-hydrophilic catheters. ${ }^{19,38-40}$ The other study did not look at a direct comparison of the two. ${ }^{37}$

- Catheter size. Only one study compared stricture formation between two different catheter sizes. There was no significant difference in urethral stricture rate between two most frequently used catheter sizes (12 and $14 \mathrm{Fr}) .^{38}$

\section{Summary}

Urethral stricture formation is a complex process and trying to isolate which catheter type may predispose to stricture formation is difficult. Many of the patients in these trials have had indwelling catheters for substantial periods of time early in their treatment, which potentially could have an effect on subsequent rates of stricture formation. In addition, patients in these trials are using various sizes of catheters and may have varying degrees of detrusor sphincter dyssynergia or prostatic enlargement which may contribute to catheter trauma. Though hydrophilic catheters appear to cause less urethral trauma, there is no data to indicate there is a decreased rate of urethral strictures based on the type or size of catheter used for IC.

\section{Patient perspective}

IC enhances both bladder emptying and storage function, relieving associated symptoms that would otherwise impair QOL. ${ }^{41}$ Furthermore, IC lessens restrictions on daily activities, promotes patient independence and improves sleep, social functioning and overall QoL. ${ }^{42-44}$

The success of IC requires that it is acceptable to the patient upfront, and that the patient is satisfied with treatment and compliant with it long-term. That in turn requires appropriate and skilled education, support and long-term follow-up by the health care team. ${ }^{41,43}$ Initial uptake and 
success may be further impacted by patient factors such as gender, body habitus and manual dexterity, and by external factors such as caregiver support and access to materials. Long-term compliance is ensured when the goals listed above are met, when interference with daily activities is minimized, and when complications and adverse effects of IC are avoided, including pain, urethral trauma, stricture formation, and UTIs. If these criteria are met, patient satisfaction is ensured resulting in improved QOL and perceived quality of care. ${ }^{45}$ Unfortunately, such ideal circumstances are not always realized, and many patients describe IC having a negative impact on QoL owing to social and psychological disturbance and UTIs. ${ }^{43,46}$ One small cross-sectional survey of 44 patients reported that only half were completely satisfied with $\mathrm{IC} .{ }^{47}$ In the NLUTD population, patients may revert to indwelling catheters, particularly those with greater disability requiring external support, younger patients, and those with persistent incontinence between catheterization (especially women who cannot use external collection devices). ${ }^{44}$

Examining the impact of IC on QoL is challenging given the heterogeneous population of patients employing it, and the multiple factors that impact QoL in these patients beyond just their use of IC. As an example, patients with SCI generally report their QoL to be worse than age- and sex-matched controls. ${ }^{48}$ Gender differences may further impact outcomes: Females have a more difficult time accessing the urethra, while men have a more difficult time with passage into the bladder. ${ }^{42}$. A validated patient reported outcome (PRO) measure has been developed to examine the impact of IC on QoL, however it has been used in only one study. ${ }^{49}$ Other authors have adapted or modified various existing questionnaires and/or incorporated simple measures such as visual analog scales, or employed a qualitative approach for the assessment. ${ }^{42,43,50}$ The important improvements that impact QoL in patients undertaking IC appear to be those related to urinary symptoms, independence, self-confidence, social relationships, and access to work activities. ${ }^{50}$ In qualitative analysis, QoL was influenced by gender, lifestyle, frequency and duration of IC, technical difficulties, type of catheter used, co-morbidities, and individual predispositions. ${ }^{43}$

High patient satisfaction and improved QoL has also been confirmed in established IC cohorts. Kessler et al studied a mixed neurogenic and non-neurogenic population of patients who had been performing IC for a mean of 5 years with an average frequency of 3 times per day using visual analogue scales to assess pain and interference with daily activities, and the Medical Outcomes Study SF-12 to evaluate QoL. ${ }^{42}$ The majority of patients found IC to be easy or very easy $(72 / 92,78.3 \%)$, and reported little or no interference with work or other daily activities (76/92, 82.6\%); moreover, nearly 90\% (80/92) reported no or minimal pain with IC. QoL was improved in $60 \%(56 / 92)$ based on questionnaire used. While this study is limited by a hybrid population, positive selection bias, use of a non-validated questionnaire, and lack of baseline data, it confirms that IC is a worthwhile strategy that is well accepted long-term and can improve patients' QoL. 
Impact of catheter type and material on patient perspective

- Hydrophilic vs uncoated catheters. Two comparative studies in children with spina bifida demonstrated a preference for single-use HC versus standard reusable PVC catheters. ${ }^{51,52}$ Qualitative research confirms this preference in community-dwelling adults; however, some patients express concern about the economic and environmental impact of singleuse catheters. ${ }^{53}$ In the review by Shamout et al,${ }^{17}$ the following observations were made regarding studies evaluating patient satisfaction and preferences:

1. Seven of nine RCTs comparing $\mathrm{HC}$ versus non-HC catheters reported significantly higher satisfaction and/or preference for $\mathrm{HC}$ catheters;

2. Two of two RCTs demonstrated patient preference for prelubricated versus nonprelubricated catheters;

3. HC catheters may be favored over prelubricated catheters; however, only one study with only 29 patients compared them;

4. Preferences may exist between various brands of $\mathrm{HC}$ catheters; and,

5. In the only study utilizing a validated QoL questionnaire, compact catheters were preferred over non-compact catheters by $63 \%$ of 125 NLUTD patients. ${ }^{54}$ Four other RCTs showed no significant difference.

Impact of catheterization technique on patient perspective

While many studies have compared catheterization techniques and materials, robust QoL data is lacking in the majority of these. Clean IC is less time consuming and less costly, compared to aseptic IC, and it improves patient QoL. ${ }^{55}$ There is no data comparing QoL in patients reusing catheters versus single use PVC catheters.

\section{Summary}

IC reduces or removes the risks associated with indwelling catheters and enhances independence and social and psychological well-being. Single-use HC catheters appear to be preferred for the majority of patients.

\section{Economic perspective}

A total of eight health economic analysis comparing different types of IC were identified. All of them were cost utility analyses (CUAs) assessing the cost-effectiveness in the UK ${ }^{56,57}$. Japan $^{58}$, the US ${ }^{59}$, Italy ${ }^{60}$, Brazil ${ }^{61}$, and Canada ${ }^{62,63}$. Each uses local input variables where possible. For the purpose of this Best Practice Report, we will focus on the Canadian studies as they are more relevant to our healthcare system.

Impact of catheter type and material on economic perspective

- Hydrophilic vs uncoated catheters. HC catheters have an estimated cost of \$7.02 in Canada. ${ }^{64}$ The Canadian analyses compared the cost-effectiveness of hydrophilic-coated 
(HC) catheters to uncoated single-use catheters (UC) ${ }^{62,63}$, while Health Quality Ontario ${ }^{62}$ also including re-use of UC catheters. They both use a Markov decision model and the index patient was a person with SCI. One study simulated a lifetime horizon, whilst Health Quality Ontario ${ }^{62}$ selected a 5 year horizon. Both models factor in antibiotic resistance, but there are some differences in which catheter related outcomes are modelled. The studies model long term sequelae of UTIs and catheterization, which include various renal complications, bladder stones, and urethral damage. However, Health Quality Ontario ${ }^{62}$ only include short-term consequences of symptomatic UTIs, with the latter suggesting a more conservative estimate. In terms of number of catherization per day, Welk et al. base their analysis on 4 catheters used per day, ${ }^{63}$ while Health Quality Ontario ${ }^{62}$ assumed 5 per day.

Health Quality Ontario ${ }^{62}$ only takes the perspective of the healthcare system, while Welk et al.$^{63}$ also included a societal perspective. They included health-related QOL (HRQoL) gains that capture indirect health-related factors associated with IC (i.e. pain related to IC, steps and time needed for the IC process). ${ }^{63}$ These values are based on the study by Averbeck et al. that generate health state utilities using an internet-based time trade-off (TTO) survey in a UK and Canadian population. ${ }^{65}$ This allows the inclusion of utilities for user preferences in the ICERcalculation. ${ }^{63} \mathrm{IC}$ with $\mathrm{HC}$ becomes more economically attractive in these scenarios as increased patient satisfaction leads to a lower cost per quality-adjusted life-year (QALY). When comparing IC with $\mathrm{HC}$ versus UC, they found $\mathrm{HC}$ catheters likely to be cost-effective. They predicted a gain of 0.72 QALYs at an additional cost of \$48,016, leading to an ICER of \$66,634/QALY. ${ }^{63}$

Health Quality Ontario ${ }^{62}$ found that the lowest cost intervention, reusing single-use UC catheters (1/week), had the highest probability of being cost-effective against all other comparators. This stems from marginal differences in QALYs found between catheter types and high $\mathrm{HC}$ catheter costs.

Impact of catheterization technique on economic perspective

- Clean vs aseptic. Randomized controlled trials have compared aseptic to clean IC in different settings such as perioperative patients, veterans in long-term care homes, and patients with SCI. ${ }^{66-68} \mathrm{~A}$ review of the literature specifically relevant to neurogenic bladder patients found the aseptic technique was associated with $277 \%$ higher costs compared to the clean technique. ${ }^{69}$ None of these studies demonstrated a significant difference in UTIs.

- Catheter practices (single use vs. reuse). Various techniques have been employed to clean and store the catheter between uses, and generally a new catheter is used either each day or each week. Estimates from Health Quality Ontario suggest that a year's supply of uncoated intermittent catheters that were reused throughout the day and then discarded 
costs approximately $\$ 558$, while using a new catheter for each catheterization costs approximately $\$ 2,232{ }^{62}$. The primary variable influencing cost effectiveness was the significant cost differences of the catheters used in the two different scenarios. While there are conflicting opinions on whether catheter reuse results in a different UTI risk, this has little effect on the model as UTI is generally considered to be a brief, timelimited condition. Limitations of this economic analysis include a lack of prior research addressing catheter reuse, and the fact that this analysis did not consider patient acceptability/satisfaction.

\section{Summary}

In summary, the use of $\mathrm{HC}$ catheters for IC is cost-effective over a lifetime horizon. Aseptic technique was associated with higher costs compared to the clean technique. Reuse of catheters appears to be a cost-effective approach; however, these results should be interpreted with caution given the limited availability of data and the large difference in resource use.

\section{Conclusions}

Our summary recommendations are shown in Table 3. IC is the gold standard for the management of failure to empty the bladder. When necessary, an indwelling catheter may be considered, and in most cases a suprapubic catheter is preferable to a long-term indwelling urethral catheter. Optimal catheter material, cleaning method and/or catheterization technique, remain controversial topics in urology. The preferred IC strategy varies by settings and practices. There is no evidence that there is one best catheter for all patients. Selection of the ideal intermittent catheter type/technique is a complex balance between patient's motor functions, acceptance of the procedure, QOL and the economic implications. Whenever possible, hydrophilic-coated or prelubricated catheters should be proposed to the patient as the first treatment option because they appear to lower the risk of UTI, may result in less urethral trauma and have higher convenience and ease of use compared to conventional uncoated catheters. Reuse of catheters may still be considered in specific clinical scenarios, however the patient should be made aware there are concerns regarding efficacy, and that there is limited evidence to support cleansing techniques for a single use product. Long-term cost-effectiveness of single-use $\mathrm{HC}$ catheters was established from the perspective of several international healthcare systems. Debate continues to linger regarding the best catheter material and/or technique in which upper urinary tract deterioration can be prevented while minimizing treatment-related morbidity. Therefore, further high-quality randomized controlled trials are warranted. 


\section{References}

1. Weld KJ, DMOCHOWSKI RR. Effect of bladder management on urological complications in spinal cord injured patients. The Journal of urology. 2000;163(3):768772.

2. Nicolle LE, Committee SL-TC. Urinary tract infections in long-term-care facilities. Infection Control \& Hospital Epidemiology. 2001;22(3):167-175.

3. Peatfield R, Burt A, Smith P. Suprapubic catheterisation after spinal cord injury: a follow-up report. Paraplegia. 1983;21(4):220-226.

4. Feifer A, Corcos J. Contemporary role of suprapubic cystostomy in treatment of neuropathic bladder dysfunction in spinal cord injured patients. Neurourology and Urodynamics: Official Journal of the International Continence Society. 2008;27(6):475479.

5. Warren JW. Catheter-associated urinary tract infections. Infectious disease clinics of North America. 1997;11(3):609-622.

6. Saint S, Lipsky BA. Preventing catheter-related bacteriuria: should we? Can we? How? Archives of Internal Medicine. 1999;159(8):800-808.

7. Lapides J, Diokno AC, Silber SJ, Lowe BS. Clean, intermittent self-catheterization in the treatment of urinary tract disease. Journal of Urology. 2002;167(2 Part 2):11311133.

8. Cornejo-Dávila V, Durán-Ortiz S, Pacheco-Gahbler C. Incidence of urethral stricture in patients with spinal cord injury treated with clean intermittent self-catheterization. Urology. 2017;99:260-264.

9. Afsar S, Yemisci O, Cosar S, Cetin N. Compliance with clean intermittent catheterization in spinal cord injury patients: a long-term follow-up study. Spinal Cord. 2013;51(8):645.

10. Hooton TM, Bradley SF, Cardenas DD, et al. Diagnosis, prevention, and treatment of catheter-associated urinary tract infection in adults: 2009 International Clinical Practice Guidelines from the Infectious Diseases Society of America. Clinical infectious diseases. 2010;50(5):625-663.

11. Garibaldi RA, Burke JP, Dickman ML, Smith CB. Factors predisposing to bacteriuria during indwelling urethral catheterization. New England Journal of Medicine. 1974;291(5):215-219.

12. RAZ R, SCHILLER D, NICOLLE LE. Chronic indwelling catheter replacement before antimicrobial therapy for symptomatic urinary tract infection. The Journal of urology. 2000;164(4):1254-1258. 
13. Breitenbucher RB. Bacterial changes in the urine samples of patients with long-term indwelling catheters. Archives of internal medicine. 1984;144(8):1585-1588.

14. Warren JW, Tenney JH, Hoopes JM, Muncie HL, Anthony WC. A prospective microbiologic study of bacteriuria in patients with chronic indwelling urethral catheters. The Journal of infectious diseases. 1982;146(6):719-723.

15. Beier MT. Management of urinary tract infections in the nursing home elderly: a proposed algorithmic approach. International Journal of Antimicrobial Agents. 1999;11(3):275-284.

16. ESCLARÍN DE RUZ A, GARCÍA LEONI E, HERRUZO CABRERA R. Epidemiology and risk factors for urinary tract infection in patients with spinal cord injury. The Journal of urology. 2000;164(4):1285-1289.

17. Shamout S, Biardeau X, Corcos J, Campeau L. Outcome comparison of different approaches to self-intermittent catheterization in neurogenic patients: a systematic review. Spinal Cord. 2017.

18. Rognoni $\mathrm{C}$, Tarricone R. Intermittent catheterisation with hydrophilic and nonhydrophilic urinary catheters: systematic literature review and meta-analyses. BMC urology. 2017;17(1):4.

19. DeFoor W, Reddy P, Reed M, et al. Results of a prospective randomized control trial comparing hydrophilic to uncoated catheters in children with neurogenic bladder. Journal of pediatric urology. 2017;13(4):373.e371-373.e375.

20. Kiddoo D, Sawatzky B, Bascu C-D, Dharamsi N, Afshar K, Moore KN. Randomized crossover trial of single use hydrophilic coated vs multiple use polyvinylchloride catheters for intermittent catheterization to determine incidence of urinary infection. The Journal of urology. 2015;194(1):174-179.

21. Mauroy B, Soret R, Bonnal JL, Fantoni JC. [Comparison of 3 self lubrificated urethral catheters: prospective study on 27 patients]. Ann Urol (Paris). 2001;35(4):223-228.

22. Giannantoni A, Di Stasi SM, Scivoletto G, Virgili G, Dolci S, Porena M. Intermittent catheterization with a prelubricated catheter in spinal cord injured patients: a prospective randomized crossover study. J Urol. 2001;166(1):130-133.

23. Salameh A, Al Mohajer M, Daroucihe RO. Prevention of urinary tract infections in patients with spinal cord injury. CMAJ. 2015;187(11):807-811.

24. Saadat SH, Shepherd S, Van Asseldonk B, Elterman DS. Clean intermittent catheterization: Single use vs. reuse. Canadian Urological Association Journal. 2019;13(2):64.

25. Håkansson $M \AA$. Reuse versus single-use catheters for intermittent catheterization: what is safe and preferred? Review of current status. Spinal Cord. 2014;52(7):511. 
26. Madero-Morales PA, Robles-Torres JI, Vizcarra-Mata G, et al. Randomized Clinical Trial Using Sterile Single Use and Reused Polyvinylchloride Catheters for Intermittent Catheterization with a Clean Technique in Spina Bifida: Short-Term Urinary Tract Infection Outcomes. The Journal of urology. 2019:10.1097/JU. 0000000000000244.

27. Foley FE. A self-retaining bag catheter: For use as an indwelling catheter for constant drainage of the bladder. The Journal of Urology. 1937;38(1):140-144.

28. Siddiq DM, Darouiche RO. New strategies to prevent catheter-associated urinary tract infections. Nature Reviews Urology. 2012;9(6):305.

29. De Ridder DJ, Everaert K, Fernandez LG, et al. Intermittent catheterisation with hydrophilic-coated catheters (SpeediCath) reduces the risk of clinical urinary tract infection in spinal cord injured patients: a prospective randomised parallel comparative trial. Eur Urol. 2005;48(6):991-995.

30. Vapnek JM, Maynard FM, Kim J. A prospective randomized trial of the LoFric hydrophilic coated catheter versus conventional plastic catheter for clean intermittent catheterization. J Urol. 2003;169(3):994-998.

31. Cardenas DD, Hoffman JM. Hydrophilic catheters versus noncoated catheters for reducing the incidence of urinary tract infections: a randomized controlled trial. Arch Phys Med Rehabil. 2009;90(10):1668-1671.

32. Spinu A, Onose G, Daia C, et al. Intermittent catheterization in the management of post spinal cord injury (SCI) neurogenic bladder using new hydrophilic, with lubrication in close circuit devices--our own preliminary results. J Med Life. 2012;5(1):21-28.

33. Sutherland RS, Kogan BA, Baskin LS, Mevorach RA. Clean intermittent catheterization in boys using the LoFric catheter. J Urol. 1996;156(6):2041-2043.

34. Stensballe J, Looms D, Nielsen PN, Tvede M. Hydrophilic-coated catheters for intermittent catheterisation reduce urethral micro trauma: a prospective, randomised, participant-blinded, crossover study of three different types of catheters. Eur Urol. 2005;48(6):978-983.

35. Biering-Sorensen F, Nielsen K, Hansen HV. Urethral epithelial cells on the surface on hydrophilic catheters after intermittent catheterization: cross-over study with two catheters. Spinal Cord. 1999;37(4):299-300.

36. Sarica S, Akkoc Y, Karapolat H, Aktug H. Comparison of the use of conventional, hydrophilic and gel-lubricated catheters with regard to urethral micro trauma, urinary system infection, and patient satisfaction in patients with spinal cord injury: a randomized controlled study. European journal of physical and rehabilitation medicine. 2010;46(4):473-479. 
37. Cornejo-Davila V, Duran-Ortiz S, Pacheco-Gahbler C. Incidence of Urethral Stricture in Patients With Spinal Cord Injury Treated With Clean Intermittent SelfCatheterization. Urology. 2017;99:260-264.

38. Krebs J, Wollner J, Pannek J. Urethral strictures in men with neurogenic lower urinary tract dysfunction using intermittent catheterization for bladder evacuation. Spinal Cord. 2015;53(4):310-313.

39. Lindehall B, Abrahamsson K, Hjalmas K, Jodal U, Olsson I, Sillen U. Complications of clean intermittent catheterization in boys and young males with neurogenic bladder dysfunction. J Urol. 2004;172(4 Pt 2):1686-1688.

40. Waller L, Jonsson O, Norlen L, Sullivan L. Clean intermittent catheterization in spinal cord injury patients: long-term followup of a hydrophilic low friction technique. J Urol. 1995;153(2):345-348.

41. Newman DK, Willson MM. Review of intermittent catheterization and current best practices. Urol Nurs. 2011;31(1):12-28, 48; quiz 29.

42. Kessler TM, Ryu G, Burkhard FC. Clean intermittent self-catheterization: a burden for the patient? Neurourol Urodyn. 2009;28(1):18-21.

43. Shaw C, Logan K, Webber I, Broome L, Samuel S. Effect of clean intermittent selfcatheterization on quality of life: a qualitative study. J Adv Nurs. 2008;61(6):641-650.

44. Wyndaele JJ. Intermittent catheterization: which is the optimal technique? Spinal Cord. 2002;40(9):432-437.

45. Blumenthal D. Part 1: Quality of care--what is it? N Engl J Med. 1996;335(12):891-894.

46. McConville A. Patients' experiences of clean intermittent catheterisation. Nurs Times. 2002;98(4):55-56.

47. Bolinger R, Engberg S. Barriers, complications, adherence, and self-reported quality of life for people using clean intermittent catheterization. $J$ Wound Ostomy Continence Nurs. 2013;40(1):83-89.

48. Kreuter M, Siosteen A, Erkholm B, Bystrom U, Brown DJ. Health and quality of life of persons with spinal cord lesion in Australia and Sweden. Spinal Cord. 2005;43(2):123129.

49. Pinder B, Lloyd AJ, Elwick H, Denys P, Marley J, Bonniaud V. Development and psychometric validation of the intermittent self-catheterization questionnaire. Clin Ther. 2012;34(12):2302-2313.

50. Fumincelli L, Mazzo A, Martins JCA, Henriques FMD, Orlandin L. Quality of life of patients using intermittent urinary catheterization. Rev Lat Am Enfermagem. 2017;25:e2906.

51. Chick HE, Hunter KF, Moore KN. Parent and child experiences using a hydrophilic or reused PVC catheter for intermittent catheterisation. J Clin Nurs. 2013;22(3-4):513-520. 
52. Kiddoo D, Sawatzky B, Bascu CD, Dharamsi N, Afshar K, Moore KN. Randomized Crossover Trial of Single Use Hydrophilic Coated vs Multiple Use Polyvinylchloride Catheters for Intermittent Catheterization to Determine Incidence of Urinary Infection. $J$ Urol. 2015;194(1):174-179.

53. Avery M, Prieto J, Okamoto I, et al. Reuse of intermittent catheters: a qualitative study of IC users' perspectives. BMJ Open. 2018;8(8):e021554.

54. Chartier-Kastler E, Amarenco G, Lindbo L, et al. A prospective, randomized, crossover, multicenter study comparing quality of life using compact versus standard catheters for intermittent self-catheterization. J Urol. 2013;190(3):942-947.

55. Lapides J, Diokno AC, Lowe BS, Kalish MD. Followup on unsterile intermittent selfcatheterization. J Urol. 1974;111(2):184-187.

56. Bermingham SL, Hodgkinson S, Wright S, Hayter E, Spinks J, Pellowe C. Intermittent self catheterisation with hydrophilic, gel reservoir, and non-coated catheters: a systematic review and cost effectiveness analysis. Bmj. 2013;346:e8639.

57. Clark JF, Mealing SJ, Scott DA, et al. A cost-effectiveness analysis of long-term intermittent catheterisation with hydrophilic and uncoated catheters. Spinal Cord. 2015.

58. Watanabe T, Yamamoto S, Gotoh M, et al. Cost-Effectiveness Analysis of Long-Term Intermittent Self-Catheterization with Hydrophilic-Coated and Uncoated Catheters in Patients with Spinal Cord Injury in Japan. LUTS: Lower Urinary Tract Symptoms. 2017;9(3):142-150.

59. Håkansson MÅ, Neovius K, Lundqvist T. Healthcare Costs Associated With Hydrophilic-Coated and Non-Coated Urinary Catheters For Intermittent Use in the United States. Urologic Nursing. 2016;36(5).

60. Rognoni C, Tarricone R. Healthcare resource consumption for intermittent urinary catheterisation: cost-effectiveness of hydrophilic catheters and budget impact analyses. BMJ open. 2017;7(1):e012360.

61. Truzzi JC, Teich V, Pepe C. Can hydrophilic coated catheters be beneficial for the public healthcare system in Brazil?-A cost-effectiveness analysis in patients with spinal cord injuries. International braz j urol. 2018;44(1):121-131.

62. Health Quality Ontario. Intermittent catheters for chronic urinary retention: a health technology assessment. Ont Health Technol Assess Ser [Internet]. Available from: http://www.hqontario.ca/evidence-to-improve-care/journal-ontario-healthtechnologyassessment-series Feb;19(1) 2019.

63. Welk B, Isaranuwatchai W, Krassioukov A, Husted Torp L, Elterman D. Costeffectiveness of hydrophilic-coated intermittent catheters compared with uncoated catheters in Canada: a public payer perspective. Journal of medical economics. 2018;21(7):639-648. 
64. Ontario HQ. Intermittent Catheters for Chronic Urinary Retention: A Health Technology Assessment. Ontario health technology assessment series. 2019;19(1):1.

65. Averbeck MA, Krassioukov A, Thiruchelvam N, Madersbacher H, Bøgelund M, Igawa Y. The impact of different scenarios for intermittent bladder catheterization on health state utilities: results from an internet-based time trade-off survey. Journal of medical economics. 2018;21(10):945-952.

66. Duffy LM, Cleary J, Ahern S, et al. Clean intermittent catheterization: safe, costeffective bladder management for male residents of VA nursing homes. J Am Geriatr Soc. 1995;43(8):865-870.

67. King RB, Carlson CE, Mervine J, Wu Y, Yarkony GM. Clean and sterile intermittent catheterization methods in hospitalized patients with spinal cord injury. Archives of physical medicine and rehabilitation. 1992;73(9):798-802.

68. Carapeti E, Andrews S, Bentley P. Randomised study of sterile versus non-sterile urethral catheterisation. Annals of the Royal College of Surgeons of England. 1996;78(1):59.

69. Lemke JR, Kasprowicz K, Worral PS. Intermittent Catheterization for Patients With a Neurogenic Bladder: Sterile Versus CleanUsing Evidence-based Practice at the Staff Nurse Level. Journal of nursing care quality. 2005;20(4):302-306.

70. Gammack JK. Use and management of chronic urinary catheters in long-term care: much controversy, little consensus. Journal of the American Medical Directors Association. 2002;3(3):162-168.

\section{Competing interests:}

Dr. Campeau has been an advisory board and speaker bureau member for Asetllas and Pfizer; has received grants/honoraria from Allergan, Astellas, and Pfizer; and has participated in clinical trials supported by Pfizer. Dr. Baverstock has been a speaker for Allergan, Astellas, BSCI, and Pfizer; and has participated in clinical trials supported by Astellas and Pfizer. Dr. Carlson has been an advisory Board member for Astellas and Pfizer; has received travel honoraria from Allergan; and has participated in clinical trials supported by Astellas and Pfizer. Dr. Elterman has been an advisory board and speakers' bureau member for Allergan, Astellas, Boston Scientific, Duchesnay, Ferring, Medtronic, and Pfizer; has received grants/honoraria from Boston Scientific and Pfizer; and has participated in clinical trials supported by Astellas, Boston Scientific, and Medtronic. Dr. Hickling has been an advisory board member for Pfizer; a speakers' bureau member for Allergan, Astellas and Pfizer; has received grants/honoraria from Allergan, Astellas and Pfizer; and has participated in clinical trials supported by Astellas. 


\section{Figures and Tables}

\section{Table 1. Common uses for chronic urinary catheters}

Bladder outflow obstruction

Neurogenic lower urinary tract dysfunction

Management of urinary incontinence

Patient preference

Healing of decubitus ulcer

Disease management (e.g., urinary diversion, monitoring diuresis)

Adapted from Gammack, $2002{ }^{70}$

Adapted from Newman \& Willson, $2011^{41}$. IC: intermittent catheterization; UTI: urinary tract

\section{Table 2. Advantages of IC over indwelling urinary catheters}

Reduced risk of common indwelling catheter-related complications (such as dislodged catheter, urethral erosion)

Reduced risk of UTIs

Less of a barrier to intimacy and sexual activity

Potential for reduced lower urinary tract symptoms between catheterizations infection. 


\begin{tabular}{|c|c|c|c|}
\hline Section & Recommendation & $\begin{array}{c}\text { Strength of } \\
\text { statement }\end{array}$ & $\begin{array}{l}\text { Quality of } \\
\text { evidence }\end{array}$ \\
\hline Type of catheter & $\begin{array}{l}\text { We recommend individualizing the selection of } \\
\text { appropriate bladder management strategy (IC, } \\
\text { indwelling urethral or suprapubic catheter) in } \\
\text { accordance with anatomic factors, bladder } \\
\text { characteristics, motor and cognitive functions, } \\
\text { patient preference and associated quality of life. }\end{array}$ & Strong & Moderate \\
\hline $\begin{array}{l}\text { Catheter-related complications: } \\
\text { UTIs }\end{array}$ & $\begin{array}{l}\text { We recommend using intermittent catheters over } \\
\text { indwelling catheters for long-term use due to a } \\
\text { lower risk of UTIs. Routine use of antimicrobial } \\
\text { coated catheters is not recommended. }\end{array}$ & Strong & Moderate \\
\hline $\begin{array}{l}\text { Catheter-related complications: } \\
\text { UTIs }\end{array}$ & $\begin{array}{l}\text { For those using intermittent catheters, we suggest } \\
\text { using single PVC (as opposed to multiple use } \\
\text { PVC), and special hydrophilic-coated catheters or } \\
\text { pre-lubricated catheters, as they may decrease the } \\
\text { frequency of UTIs. }\end{array}$ & Weak & Low \\
\hline $\begin{array}{l}\text { Catheter-related complications: } \\
\text { Urethral trauma }\end{array}$ & $\begin{array}{l}\text { We suggest using hydrophilic catheters as they } \\
\text { may cause less urethral trauma. }\end{array}$ & Weak & Moderate \\
\hline $\begin{array}{l}\text { Catheter-related complications: } \\
\text { Urethral trauma }\end{array}$ & $\begin{array}{l}\text { There is no evidence to suggest that the type of } \\
\text { intermittent catheter impacts urethral stricture } \\
\text { formation. }\end{array}$ & Weak & Weak \\
\hline Patient perspective & $\begin{array}{l}\text { We recommend offering hydrophilic or } \\
\text { prelubricated catheters to patients because of an } \\
\text { improved bladder related QOL. }\end{array}$ & Strong & Moderate \\
\hline Economic analysis & $\begin{array}{l}\text { We suggest offering patients, if possible, HC } \\
\text { catheters, as they are cost-effective compared to } \\
\text { single-use uncoated catheters due to the } \\
\text { decreased incidence of UTIs and increased QOL. }\end{array}$ & Moderate & Moderate \\
\hline
\end{tabular}

IC: intermittent catheterization; QOL: quality of life; UTI: urinary tract infection. 